\title{
Synthesis and structural studies of copper(II) complex supported by -ONNO- tetradentate ligand: Efficient catalyst for the ring-opening polymerization of lactide
}

\author{
Anita Routaray a, Nibedita Nath a, Somanath Mantri a , Tungabidya Maharana ${ }^{\text {b,*, }}$ \\ Alekha Kumar Sutar a,\# \\ a Catalysis Research Lab, Department of Chemistry, Ravenshaw University, Cuttack-3, Odisha, India \\ ${ }^{\mathrm{b}}$ Department of Chemistry, National Institute of Technology, Raipur, India
}

\section{A R T I C L E I N F O}

\section{Article history:}

Received 12 December 2014

Accepted 12 January 2015

Published 20 May 2015

\section{Keywords:}

Ring-opening polymerization

Lactide

Copper complex

Polylactic acid

\begin{abstract}
A B S T R A C T
The -ONNO- tetradentate Schiff base ligand $N, N^{\prime}$-bis(2-hydroxy-3-methoxybenzaldehyde)benzene1,2-diamine (HMBBD) has been synthesized. The ligand was attached to copper (Cu-HMBBD) in methanol under $\mathrm{N}_{2}$ atmosphere to give a mononuclear complex. The reactivity of this complex in the ring-opening polymerization (ROP) of lactide has been studied. The complex has a square planner geometry, as determined by X-ray diffraction studies. The copper complex is highly active towards the ring-opening polymerization of lactide, and the rate of polymerization is heavily dependent on the initiator used. The copper complex allows controlled ring-opening polymerization, as shown by the linear relationship between the percentage conversion and the number average molecular weight. Based on the literature, a mechanism for the ROP of lactide has been proposed.
\end{abstract}

(C) 2015, Dalian Institute of Chemical Physics, Chinese Academy of Sciences. Published by Elsevier B.V. All rights reserved.

\section{Introduction}

The synthesis of polymers with accurately prepared architectures (controlled molecular weights) and promising properties has been a constant challenge for polymer scientists. Organic polymer chemists commonly adapt known organic reactions to control the way compounds of low molecular weights are converted into polymers of high molecular weights. However, living polymerization offers similar or better control and was first discovered by Szwarc [1] and thereafter, Matyjaszewski et al. [2] developed the controlled cationic and radical vinyl polymerizations. Similarly, a number of coordination and metathesis polymerizations, as well as ring-opening polymerizations (ROPs) were found to operate in a living polymerization manner [3]. A wide variety of cyclic organic compounds have been investigated via ROP to give the polymers with novel architectures. The ROP of lactide has received renewed attention in recent years as it allows for control of the copolymer microstructures in ways that would be difficult to achieve by conventional polymerization methods. Many polymer chemists have polymerized lactide using different metal complexes (transition and lanthanide) as catalysts/initiators, incorporating bi-dentate, tri-dentate and tetra-dentate ligands. Of the various methods that have been employed, metal containing initiators have achieved increasing industrial importance [4,5]. The limiting use in biomedical applications is the extent to which the metal residues can be removed upon quenching the polymerization. As the removal of metal can

\footnotetext{
* Corresponding author. Tel: +91-771-2254200; Fax: +91-771-2254600; E-mail: mtungabidya@gmail.com

\# Corresponding author. Tel: +91-671-2610060; Fax: +91-671-2610304; E-mail: dralekhasutar@gmail.com

This work was supported by DST, CSIR and UGC, New Delhi, India.

DOI: 10.1016/S1872-2067(14)60293-X | http://www.sciencedirect.com/science/journal/18722067 | Chin. J. Catal., Vol. 36, No. 5, May 2015
} 
never be complete, it is preferred that a feasible industrial process should employ metals that are not cytotoxic. When the process uses environmentally benign metals that are part of the mammalian anatomy, there should be no harm from the metal [6].

Most recently, metal alkoxides (e.g., Al [7-9], Li [10-12], Mg [13-18], Fe [19], Sn [20,21], Ti [22,23] or Zn [24-27]) have proved to be efficient catalysts for the ROP of lactide, because they initiate the living ring-opening polymerization and produce polymers with both well-controlled molecular weights and narrow molecular weight distributions. Copper complexes have high electron transfer ability, moderate Lewis acidity and are stable with respect to the reactive intermediates of ROP, and are a prime target for ROP investigations. $\mathrm{Cu}$ is also a biocompatible metal and is required for life. To the best of our knowledge there have been few reports on copper initiators involving $\mathrm{N}$-containing polydentate ligands in ROP of lactide. This group of ligand is one of the most versatile ligand classes in both main group and transition metal coordination chemistry and allows for the facile modulation of steric and electronic factors [28]. The copper complexes that have been reported include those derived from pyrazole [29], phenoxy-ketimine [30], salicylaldimine [31,32], salen ligands [33] and diketiminate [34], which are active in the polymerization of lactides and produced polymers with a moderate number average molecular weights and narrow molecular weight distribution. Appavoo et al. [29] reported the polymerization of D,L-lactide in toluene at a 100:1 ratio using copper pyrazole at $110^{\circ} \mathrm{C}$, giving $M_{\mathrm{w}}=1780 \mathrm{Da}$ and PDI $=1.84$ and this shows the typical formation of low molecular weight polymers. Similarly, ROP of L-lactide at a $200: 1$ ratio at $160{ }^{\circ} \mathrm{C}$ produced low molecular weight polymers [30]. The literature has many examples of Schiff base complexes that have multiple applications in different organic transformation reactions [35,36], but there have been no systematic studies of nitrogen-containing polydentate ligand complexes like the copper complex of $N, N^{\prime}$-bis(2-hydroxy-3-methoxybenzaldehyde)benzene-1,2-diamine (HMBBD).

Although the lactide polymerization by transition metal complexes with $\mathrm{N}$-containing polydentate ligands has been reported [28], the copper complex of HMBBD has not been reported; hence, we report the synthesis, structural characterization and catalysis studies of the $\mathrm{Cu}$ complex of HMBBD for the ROP of lactide.

\section{Experimental}

\subsection{Materials}

Syntheses were performed under a dry $\mathrm{N}_{2}$ atmosphere using a combination of a glove box and standard Schlenk techniques. All solvents were of analytical grade and were dried and distilled prior to use. Toluene and $\mathrm{CH}_{2} \mathrm{Cl}_{2}$ were dried and distilled from sodium benzophenone and $\mathrm{P}_{2} \mathrm{O}_{5}$, respectively. Anhydrous copper chloride and 1,2-diaminobenzene were purchased from HiMedia Laboratories Pvt. Ltd., Mumbai, India. 2-Hydroxy-3-methoxybenzaldehyde and benzyl alcohol were procured from E. Merck, India. L-lactide was obtained from
Sigma-Aldrich and used as received. Other chemicals were of analytical grade (>99.0 wt $\%$ ) and used as received.

\subsection{Characterization of the HMBBD Schiff base and its copper complex}

Fourier transform infrared (FT-IR) spectra were recorded as a $\mathrm{KBr}$ pellet using a Perkin-Elmer 1600 FTIR Spectrophotometer. Electronic spectra were recorded on a Shimadzu 1601 PC UV-Vis Spectrophotometer as a sample mull in a cuvette. Thermo gravimetric analysis (TGA) was carried out using a Perkin-Elmer Pyris, Diamond Thermal Analyzer under a $\mathrm{N}_{2}$ atmosphere at a heating rate of $10{ }^{\circ} \mathrm{C} / \mathrm{min}$. The loading of metal ions in the Schiff base was determined by analyzing the loading solution with a Perkin-Elmer 3100 Atomic Absorption Spectrometer at $\lambda_{\max }$ of copper ions. The composition of the HMBBD Schiff base and its copper complex was estimated using a Haraeus Carlo Ebra 1108 Elemental Analyzer. The ${ }^{1} \mathrm{H}-\mathrm{NMR}$ spectra were recorded on an FT-NMR Brucker $300 \mathrm{MHz}$ Spectrometer using DMSO- $\mathrm{d}^{6}$ as the solvent and tetramethylsilane (TMS) as an internal reference. The magnetic moment $(\mu)$ of metal complexes was measured using a Vibrating Sample Magnetometer-155. The molecular weight of the HMBBD Schiff base and its copper complex was determined using a Vapor Pressure Osmometer (Merck VAPRO 5600, Germany). Suitable crystals of the ligand were analyzed on a Bruker Kappa Apex-II diffractometer.

\subsection{Synthesis of HMBBD Schiff base and its copper complex}

The HMBBD Schiff base was synthesized by a modification of a procedure reported in the literature $[37,38]$. A mixture of 2-hydroxy-3-methoxybenzaldehyde (20.00 mmol, $3.04 \mathrm{~g})$ and 1,2-diaminobenzene $(10.00 \mathrm{mmol}, 1.08 \mathrm{~g})$ in methanol was refluxed at $60{ }^{\circ} \mathrm{C}$ for about $2 \mathrm{~h}$. The reaction mixture was cooled to low temperature, producing orange crystals, which were filtered and recrystallized from chloroform. Yield $=94.4 \%$. Elem. Anal.: Found (\%): $\mathrm{C}=70.35, \mathrm{~N}=7.02$ and $\mathrm{H}=5.70$; Calcd $\mathrm{C}_{22} \mathrm{H}_{20} \mathrm{~N}_{2} \mathrm{O}_{4}$ (\%): $\mathrm{C}=70.20, \mathrm{~N}=7.44$ and $\mathrm{H}=5.36$. The copper complex of the HMBBD Schiff base was prepared by taking 100 $\mathrm{mL}$ of a methanolic solution of the Schiff base $(20.00 \mathrm{mmol}$, $7.53 \mathrm{~g}$ ) and $20.00 \mathrm{mmol}$ (2.69 g) of the copper salt in a round bottom flask and refluxing at $60{ }^{\circ} \mathrm{C}$ for $5 \mathrm{~h}$. All reactions were performed under a nitrogen atmosphere. The copper complex was recrystallized from methanol and dried in a vacuum desiccator. Elem. Anal.: Found (\%): $\mathrm{C}=61.75, \mathrm{~N}=6.24$ and $\mathrm{H}=4.21$; Calcd $\mathrm{C}_{22} \mathrm{H}_{18} \mathrm{CuN}_{2} \mathrm{O}_{4}(\%): \mathrm{C}=60.34, \mathrm{~N}=6.40$ and $\mathrm{H}=4.14$. The loading of copper ions in HMBBD was calculated as the complexation of metal ion using the following equation: Complexation of copper ion = amount of copper loaded/amount of Schiff base used for loading $\times 100 \%$.

\subsection{Cu-HMBBD complex in the ring-opening polymerization of L-lactide}

The synthesis of polylactic acid (PLA-150) at room temperature shows a typical polymerization procedure. L-lactide $(0.72$ 


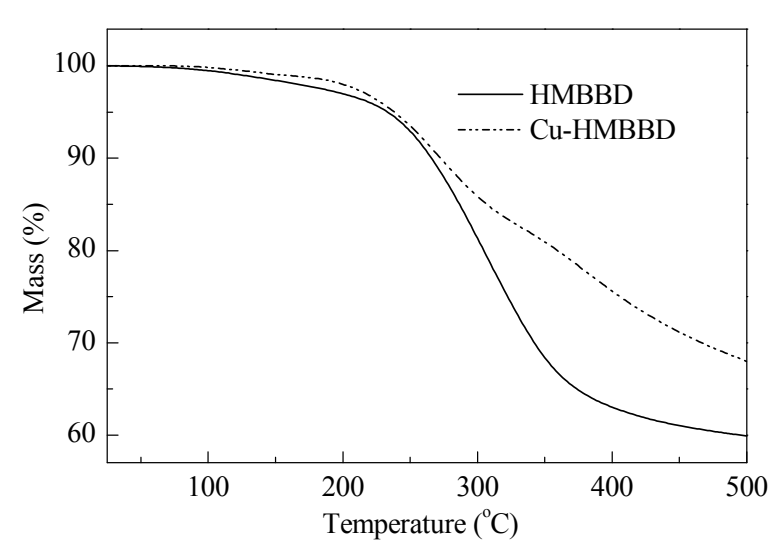

Fig. 1. Thermal stability of the HMBBD Schiff base and its copper complex.

g, $20 \mathrm{mmol}$ ) and a requisite amount of benzyl alcohol were added to a rapidly stirred solution of Cu-HMBBD $(0.058 \mathrm{~g}$, $0.133 \mathrm{mmol})$ in toluene $(20 \mathrm{~mL})$. A rise in the viscosity was observed, and the stirring was ceased after $24 \mathrm{~h}$. Volatile materials were removed under vacuum, and the residue was extracted with THF (30 mL). The extraction was dried and the white precipitate washed with $n$-hexane three times before being dried under vacuum overnight, giving a crystalline white solid (0.58 g, yield: $81 \%$ ).

\section{Results and discussion}

\subsection{Synthesis and characterization of the HMBBD Schiff base and its copper complex}

he thermal stability of the Cu-HMBBD catalysts was analyzed for their applications in high-temperature reactions, and to provide proof for the complexation of copper ion to the HMBBD Schiff base. The TGA of the HMBBD Schiff base showed a $40.1 \%$ weight loss at $500{ }^{\circ} \mathrm{C}$, but its copper complex showed a $32.0 \%$ weight loss at the same temperature (Fig. 1). The copper complex started to decompose at $150{ }^{\circ} \mathrm{C}$ whereas the ligand was only stable until $100{ }^{\circ} \mathrm{C}$. This shows that the copper complex is more stable [39]. In addition to the thermal analysis, HMBBD and its copper complex were also characterized by IR and UV spectroscopies to provide proof metal ions had complexed to the ligand. These would also help to determine the structure and geometry of the copper complex based primarily on the elemental analysis and magnetic properties of metal complex.

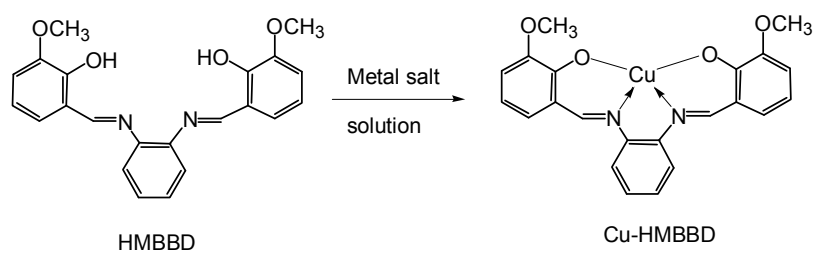

Scheme 2. Coordination of the copper ion to HMBBD.

The HMBBD Schiff base was obtained in excellent yield from the simple reaction of the two starting materials (94.4\%) (Scheme 1). The elemental analysis of HMBBD corresponds to the empirical formula $\left(\mathrm{C}_{22} \mathrm{H}_{20} \mathrm{~N}_{2} \mathrm{O}_{4}\right)$ of HMBBD [37,38]. The molecular weight of the Schiff base was $377.68 \mathrm{~g} / \mathrm{mol}$ (Calcd.: $376.41 \mathrm{~g} / \mathrm{mol}$ ). The copper ions were coordinated to the HMBBD Schiff base by refluxing a mixture of the two at $60{ }^{\circ} \mathrm{C}$ for $7 \mathrm{~h}$ (Scheme 2). The copper complex after separation and purification was analyzed for the metal ions loading by atomic absorption spectroscopy and was found to be $86.27 \mathrm{wt} \%$. The elemental analysis of $\mathrm{Cu}-\mathrm{HMBBD}$ complex corresponded to the empirical formula of the $\mathrm{Cu}-\mathrm{HMBBD}$ complex $\left(\mathrm{C}_{22} \mathrm{H}_{18} \mathrm{CuN}_{2} \mathrm{O}_{4}\right)$.

The IR spectrum (Fig. 2) of HMBBD has absorption bands at $1609 \mathrm{~cm}^{-1}(>\mathrm{C}=\mathrm{N}), 1260 \mathrm{~cm}^{-1}(>\mathrm{C}-\mathrm{O})$ phenolic and a broad
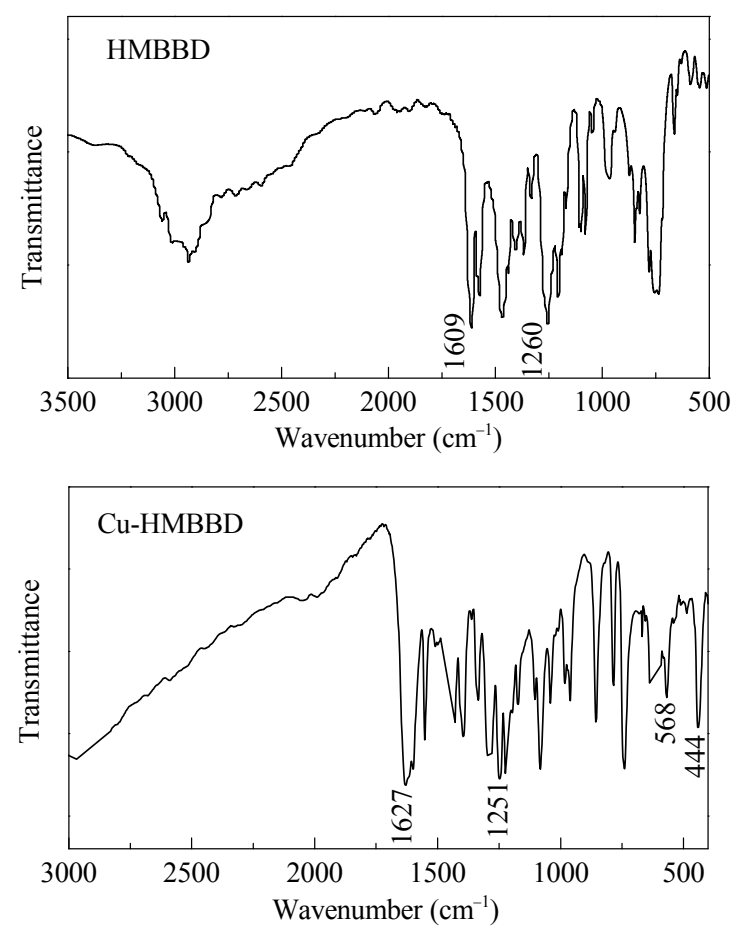

Fig. 2. FTIR spectra of HMBBD and Cu-HMBBD.<smiles>COc1cccc(/C=N/c2ccccc2/N=C/c2cccc(OC)c2O)c1O</smiles>

Scheme 1. Synthesis of $N, N^{\prime}$-bis(2-hydroxy-3-methoxybenzaldehyde)benzene-1,2-diamine. 
Table 1

FTIR frequencies and electronic transitions in HMBBD and its copper complex.

\begin{tabular}{|c|c|c|c|c|c|c|c|c|c|}
\hline \multirow{2}{*}{ Compound } & \multicolumn{5}{|c|}{ Absorption frequencies $\left(\mathrm{cm}^{-1}\right)$} & \multicolumn{4}{|c|}{ Frequencies $\lambda_{\max }(\mathrm{nm})$} \\
\hline & $V=N$ & $v x_{-0}$ & $\mathrm{VOH}$ & $\mathrm{UM}-\mathrm{O}_{\mathrm{O}}$ & $U_{\mathrm{M}-\mathrm{N}}$ & $\pi \rightarrow \pi *$ & $\mathrm{n} \rightarrow \pi^{*}$ & $\mathrm{C} \rightarrow \mathrm{T}$ & $\mathrm{d} \rightarrow \mathrm{d}$ \\
\hline HMBBD & 1609 & 1260 & $2850-3050$ & - & - & 260 & 330 & - & - \\
\hline Cu-HMBBD & 1627 & 1251 & - & 568 & 444 & 250 & 326 & 347 & 443 \\
\hline
\end{tabular}

band between 3050 and $2850 \mathrm{~cm}^{-1}$, which was assigned to the phenolic $\mathrm{OH}$. Complexation of the copper ion to HMBBD resulted in significant shifts in the $>\mathrm{C}=\mathrm{N}$ and $>\mathrm{C}-\mathrm{O}$ absorptions (18 and $9 \mathrm{~cm}^{-1}$, respectively) and new absorption bands due to the formation of $\mathrm{Cu}-\mathrm{O}\left(568 \mathrm{~cm}^{-1}\right)$ and $\mathrm{Cu}-\mathrm{N}$ bonds $\left(444 \mathrm{~cm}^{-1}\right)$. The disappearance of the phenolic absorption band on complexation was additional evidence for the inclusion of metal ions in the complex (Table 1) [37,38].

The complexation of metal ions to the Schiff base was further confirmed by comparing the electronic spectra of metal complexes and pure HMBBD. The electronic spectra of HMBBD (Fig. 3) show absorption bands at 260 and $330 \mathrm{~nm}$, which were assigned to $\pi \rightarrow \pi^{*}$ and $n \rightarrow \pi^{*}$ transitions. The Cu-HMBBD complex exhibits a hypsochromic shift in the $\pi \rightarrow \pi{ }^{*}$ transition from 260 to $250 \mathrm{~nm}$, and in the $\mathrm{n} \rightarrow \pi^{*}$ transition from 330 to $326 \mathrm{~nm}$ (Table 1, Fig. 3). Two additional bands, a $\mathrm{C} \rightarrow \mathrm{T}$ transition and a $\mathrm{d} \rightarrow \mathrm{d}$ transition, appeared at 347 and $443 \mathrm{~nm}$, respectively. These electronic transitions correspond to the $\mathrm{t}_{2} \mathrm{~g}^{6}$ and $\mathrm{eg}^{3}$ configurations for the copper(II) ion in this complex. The magnetic moment $(\mu)$ of the Cu-HMBBD complex was found to be 1.89 $\mathrm{BM}$, which indicated that it was paramagnetic and most likely in a square planar structure with $\mathrm{dsp}^{2}$ hybridization.

Single crystals of HMBBD suitable for XRD measurement crystallized in the monoclinic space group $P 21 / c$. Crystallographic data and the results of structure refinements are summarized in Table 2, and the crystal structure is shown in Scheme 3. This shows that each 2-hydroxy-3-methoxybenzaldehyde binds to one of the two diaminobenzene nitrogens. Selected bond lengths ( $\AA$ ) and bond angles (deg): O(2)-C(16) 1.348(2); O(1)-C(10) 1.354(3); N(2)-C(8) 1.274(3); N(2)-C(2) 1.425(3); $\mathrm{O}(3)-\mathrm{C}(17) \quad 1.364(3) ; \quad \mathrm{O}(3)-\mathrm{C}(21) \quad 1.417(3) ;$ $\mathrm{N}(1)-\mathrm{C}(7)$ 1.279(3); N(1)-C(1) 1.410(3); O(4)-C(11) 1.365(3); $\mathrm{O}(4)-\mathrm{C}(22)$ 1.423(3); C(15)-C(7) 1.436(3); C(9)-C(8) 1.457(3); $\mathrm{O}(2)-\mathrm{C}(16)-\mathrm{C}(15) \quad 122.5(2) ; \quad \mathrm{O}(2)-\mathrm{C}(16)-\mathrm{C}(17) \quad 117.6(2) ;$ $\mathrm{C}(8)-\mathrm{N}(2)-\mathrm{C}(2) \quad 118.4(2) ; \quad \mathrm{C}(17)-\mathrm{O}(3)-\mathrm{C}(21) \quad 117.8(2) ;$

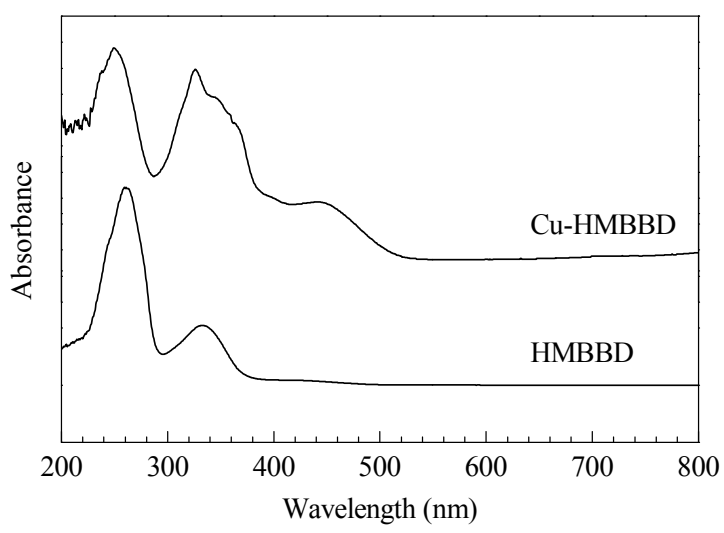

Fig. 3. UV-Vis spectra of HMBBD and its copper complex.

$\begin{array}{lccr}\mathrm{C}(7)-\mathrm{N}(1)-\mathrm{C}(1) & 123.5(2) ; & \mathrm{C}(2)-\mathrm{C}(1)-\mathrm{N}(1) & 116.5(2) ; \\ \mathrm{C}(6)-\mathrm{C}(1)-\mathrm{N}(1) & 124.7(2) ; & \mathrm{N}(1)-\mathrm{C}(7)-\mathrm{C}(15) & 121.3(2) ; \\ \mathrm{O}(3)-\mathrm{C}(17)-\mathrm{C}(18) & 125.7(2) ; & \mathrm{O}(3)-\mathrm{C}(17)-\mathrm{C}(16) & 114.6(2) ; \\ \mathrm{C}(3)-\mathrm{C}(2)-\mathrm{N}(2) & 121.4(2) ; & \mathrm{C}(1)-\mathrm{C}(2)-\mathrm{N}(2) & 118.5(2) ; \\ \mathrm{O}(1)-\mathrm{C}(10)-\mathrm{C}(9) & 122.3(2) ; & \mathrm{O}(1)-\mathrm{C}(10)-\mathrm{C}(11) & 117.7(2) ; \\ \mathrm{O}(4)-\mathrm{C}(11)-\mathrm{C}(12) & 125.3(2) ; & \mathrm{O}(4)-\mathrm{C}(11)-\mathrm{C}(10) & 15.1(2) ;\end{array}$

Table 2

Crystal data of HMBBD and structure refinement parameters.

\begin{tabular}{|c|c|}
\hline Emp. form. & $\mathrm{C}_{22} \mathrm{H}_{20} \mathrm{~N}_{2} \mathrm{O}_{4}$ \\
\hline Form. wt & 376.41 \\
\hline Temp. (K) & $293(2)$ \\
\hline$\lambda(\AA)$ & 0.71073 \\
\hline Crystal system & monoclinic \\
\hline Space group & $P 2_{1} / c$ \\
\hline$a(\AA)$ & $6.6546(2)$ \\
\hline$b(\AA)$ & $16.8579(7)$ \\
\hline$c(\AA)$ & $17.1749(7)$ \\
\hline$\alpha\left({ }^{\circ}\right)$ & 90 \\
\hline$\beta\left(^{\circ}\right)$ & $93.958(3)$ \\
\hline$\gamma\left(0^{\circ}\right)$ & 90 \\
\hline$V\left(\AA^{3}\right)$ & $1908.17(13)$ \\
\hline$Z$ & 4 \\
\hline$\rho\left(\mathrm{mg} / \mathrm{m}^{3}\right)$ & 1.310 \\
\hline$\mu(\mathrm{Mo} \mathrm{K} \alpha)\left(\mathrm{mm}^{-1}\right)$ & 0.091 \\
\hline$F(000)$ & 792 \\
\hline Crystal size $\left(\mathrm{mm}^{3}\right)$ & $0.52 \times 0.50 \times 0.23$ \\
\hline$\theta$ range $\left({ }^{\circ} \mathrm{C}\right)$ & $1.701-25.739$ \\
\hline Index ranges & $-8 \leq h \leq 7,-20 \leq k \leq 20,-20 \leq l \leq 20$ \\
\hline Reflections collected & 20366 \\
\hline Independent reflections & 3614 \\
\hline$R$ (int) & 0.0713 \\
\hline Completeness to $\theta=25.242^{\circ}$ & $99.9 \%$ \\
\hline Refinement method & Full-matrix least-squares on $F^{2}$ \\
\hline GOF & 0.991 \\
\hline Final $R$ indices $(I>2 \rho(I))$ & $R_{1}=0.1183, \mathrm{w} R_{2}=0.1454$ \\
\hline$R$ indices & $R_{1}=0.1183, \mathrm{w} R_{2}=0.1454$ \\
\hline Extinction coefficient & $\mathrm{n} / \mathrm{a}$ \\
\hline$\rho_{\min }-\rho_{\max }\left(\mathrm{e} \AA^{-3}\right)$ & 0.143 and -0.189 \\
\hline
\end{tabular}

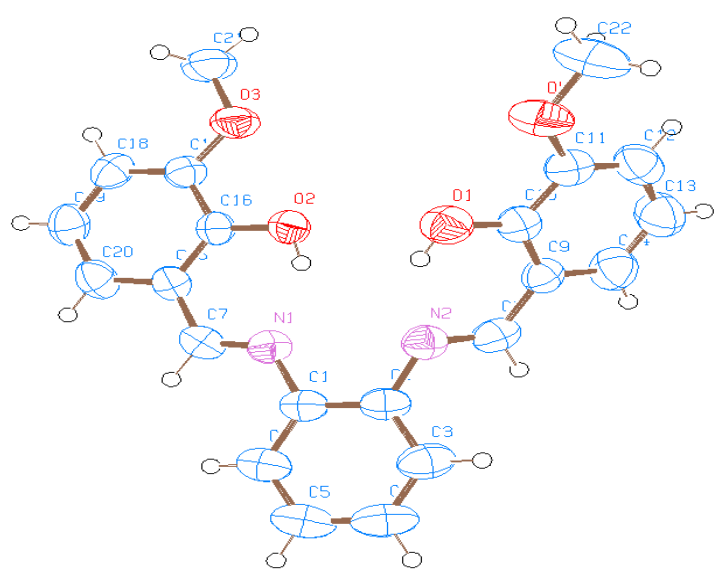

Scheme 3. Crystal structure of HMBBD. 


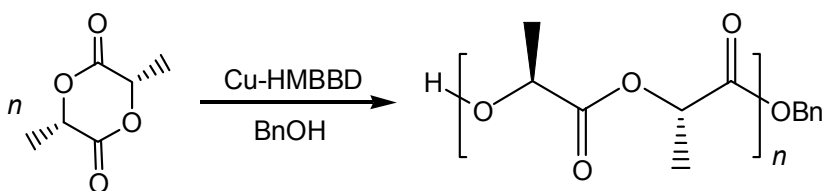

Scheme 4. Ring-opening polymerization of lactide.

$\mathrm{N}(2)-\mathrm{C}(8)-\mathrm{C}(9) 122.2(2)$.

\subsection{Cu-HMBBD complex in the ring-opening polymerization of L-lactide}

On the basis of the "immortal" property of lactide polymerization, demonstrated by several copper complexes [29-34], and evidence of in situ formation of a metal alkoxide in the presence of an alcohol [7-27], the complex Cu-HMBBD was expected to behave as a catalyst in the ROP of lactide in the presence of benzyl alcohol. Cu-HMBBD does initiate the ROP of L-lactide (LA) in the presence of benzyl alcohol in dichloromethane at $30{ }^{\circ} \mathrm{C}$ (Scheme 4). The polymerization results are listed in Tables 3 and 4 . All runs displayed high activities for the polymerization of L-lactide and great control of the molecular weight. The presence of benzyl alcohol has a significant influence on the polymerization behavior of the Cu-HMBBD.

This ROP of L-lactide using Cu-HMBBD with a monomer to benzyl alcohol ratio of 150/1 has been systematically studied at $30{ }^{\circ} \mathrm{C}$ (Table 3). It is worth noting that $\mathrm{Cu}$-HMBBD is more active in $\mathrm{CH}_{2} \mathrm{Cl}_{2}$ than in toluene or in THF. The slowest polymerization rate was found in THF, probably because of coordination of the THF to the copper metal, thus slowing the reaction rate. Toluene is a non-polar solvent and $\mathrm{CH}_{2} \mathrm{Cl}_{2}$ is a polar aprotic solvent. Based on the mechanism (Scheme 5), the polar solvent

Table 3

Polymerization of L-lactide using $\mathrm{Cu}-\mathrm{HMBBD}$ in $\mathrm{CH}_{2} \mathrm{Cl}_{2}$ at $30^{\circ} \mathrm{C}$.

\begin{tabular}{lccc}
\hline Solvent & $\begin{array}{c}\text { Conversion } \\
(\%)\end{array}$ & $\begin{array}{c}M_{n} \text { (Theory) }^{\mathrm{b}} \\
(\mathrm{g} / \mathrm{mol})\end{array}$ & $\begin{array}{c}M_{n}(\mathrm{VPO})^{\mathrm{c}} \\
(\mathrm{g} / \mathrm{mol})\end{array}$ \\
\hline $\mathrm{CH}_{2} \mathrm{Cl}_{2}$ & 92.4 & 20100 & 22900 \\
Toluene & 80.7 & 17500 & 19400 \\
THF & 56.5 & 12300 & 17100 \\
\hline
\end{tabular}

Reaction conditions: [LA $]_{0}=20 \mathrm{mmol}$, room temperature, $24 \mathrm{~h}$ $[\mathrm{M}]_{0} /[\mathrm{Cu}] /[\mathrm{BnOH}]=150 / 1 / 1$.

a Percentage conversion of the monomer calculated by (weight of polymer recovered/weight of monomer $) \times 100 \%$.

${ }^{\mathrm{b}}$ Calculated by $\left([\mathrm{LA}]_{0} /[\mathrm{BnOH}]\right) \times 144.13 \times$ conversion +108.14

c Determined by VPO [40].

Table 4

Polymerization of L-lactide by copper complex (Cu-HMBBD) in the presence of benzyl alcohol.

\begin{tabular}{lccccc}
\hline Entry & $\begin{array}{c}{[\mathrm{LA}]_{0} /} \\
{[\mathrm{Cu}] /[\mathrm{BnOH}]}\end{array}$ & $\begin{array}{c}\text { Time } \\
(\mathrm{h})\end{array}$ & $\begin{array}{c}\text { Conversion } \\
(\%)\end{array}$ & $\begin{array}{c}M_{n} \text { (Theory) } \\
(\mathrm{g} / \mathrm{mol})\end{array}$ & $\begin{array}{c}M_{n}(\mathrm{VPO}) \\
(\mathrm{g} / \mathrm{mol})\end{array}$ \\
\hline 1 & $100: 1: 0$ & 24 & $<5$ & $-\mathrm{a}$ & $-\mathrm{a}$ \\
2 & $50: 1: 1$ & 24 & 78.6 & 5800 & 7300 \\
3 & $100: 1: 1$ & 24 & 88.9 & 12900 & 15100 \\
4 & $150: 1: 1$ & 24 & 92.4 & 20100 & 22900 \\
5 & $200: 1: 1$ & 24 & 94.6 & 27400 & 28600 \\
6 & $100: 1: 2$ & 20 & 91.2 & 6700 & 7900 \\
7 & $100: 1: 4$ & 15 & 93.3 & 3500 & 4100 \\
\hline
\end{tabular}

Reaction conditions: $[\mathrm{LA}]_{0}=20 \mathrm{mmol}$, room temperature, $\mathrm{CH}_{2} \mathrm{Cl}_{2} 30 \mathrm{~mL}$. a Data not available.
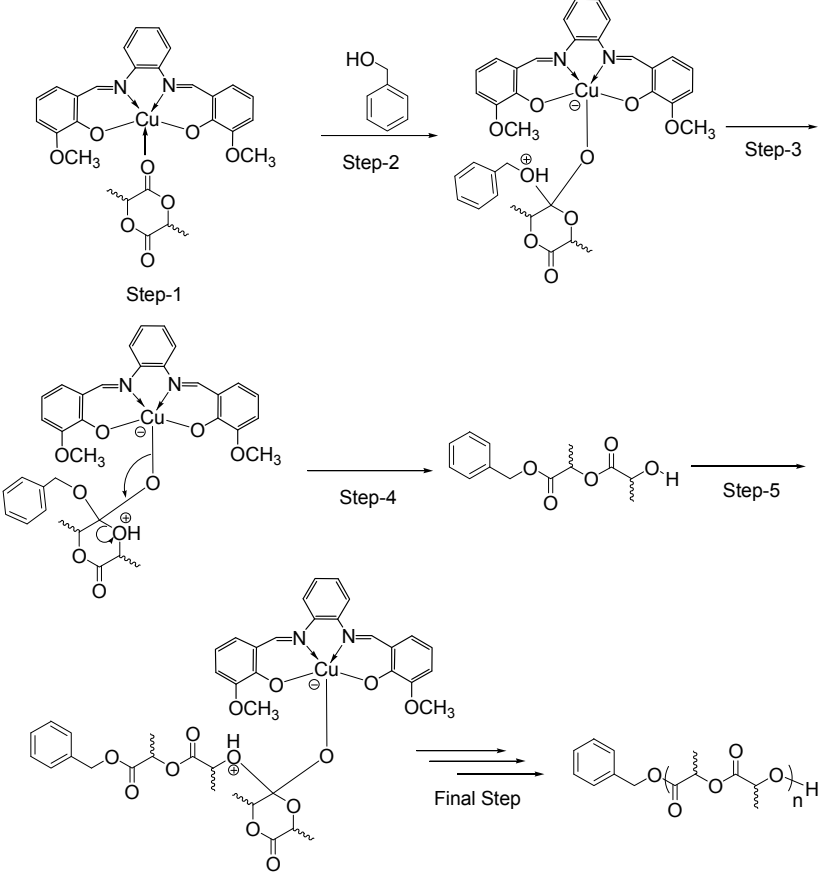

Scheme 5. Reaction steps in the ROP of L-lactide.

should give a higher polymerization rate.

From the polymerization results listed in Table 4, several structure-activity trends may be drawn. These results indicate that $\mathrm{Cu}$-HMBBD is an efficient catalyst for ROP of L-lactide in the presence of $\mathrm{BnOH}$, when the $[\mathrm{LA}] /[\mathrm{BnOH}]$ ratio is $50-200$. The polymerization is well controlled and the "living" character is demonstrated by the linear relationship between $M_{n}$ and the $[\mathrm{LA}] /[\mathrm{BnOH}]$ ratio (Fig. 4). The "immortal" character of this reaction was examined by using two or four equivalents of benzyl alcohol as a chain transfer agent (Table 4, entries 6 and 7). It was found that for the polymerization without $\mathrm{BnOH}$, there is almost negligible conversion $(<5 \%)$, but the use of $\mathrm{BnOH}$ drastically changes the activity of the catalyst. The use of more $\mathrm{BnOH}$ (entries 6 and 7) decreases the reaction time from 24 to $11 \mathrm{~h}$. This may be because the initiator is actively participating in the polymerization reaction. The molecular weight of the polymers was also affected by the ratio of $\mathrm{BnOH}$ used. By adding two or four equivalents of benzyl alcohol to the

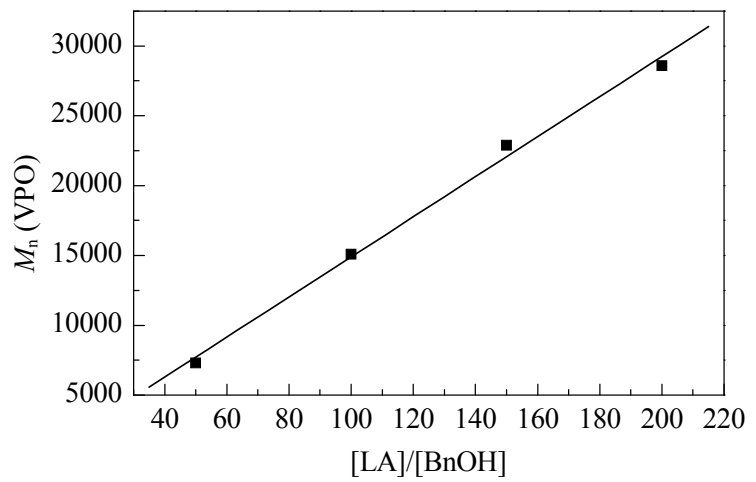

Fig. 4. Polymerization of L-lactide catalyzed by $\mathrm{Cu}-\mathrm{HMBBD}$ in $\mathrm{CH}_{2} \mathrm{Cl}_{2}$ at room temperature. 


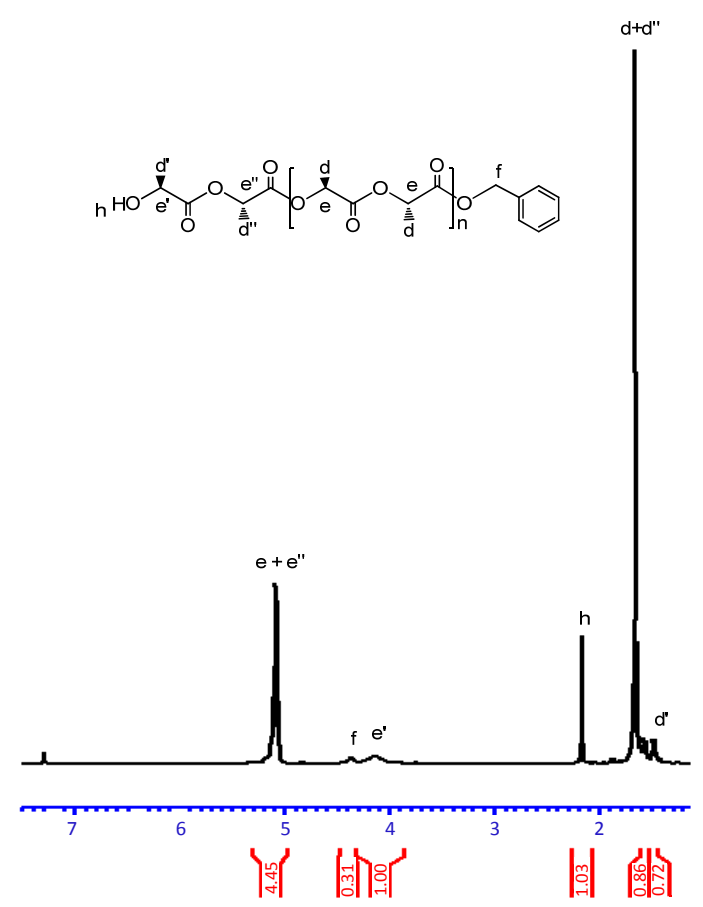

Fig. 5. ${ }^{1} \mathrm{H}$ NMR spectrum of PLLA-150 (150 indicates a $[\mathrm{LA}]_{0} /[\mathrm{BnOH}]$ ratio of 150$)$.

polymerization reactions, the molecular weights were halved or quartered, respectively.

To understand the initiation process, ${ }^{1} \mathrm{H}$ NMR studies on the poly-L-lactide (PLLA) as formed by $\mathrm{Cu}$-HMBBD with $\mathrm{BnOH}$ as an initiator have been performed. The ${ }^{1} \mathrm{H}$ NMR spectrum of PLLA-150 (Fig. 5), prepared from a $[\mathrm{LA}]_{0} /[\mathrm{BnOH}]$ ratio of 150 , indicates that the polymer chain is capped with a benzyl ester group on one end and a hydroxyl group on the other. This suggests that the initiation occurred through the insertion of the benzyl alkoxy group into L-lactide, giving a copper alkoxide intermediate, which further reacts with an excess of L-lactide to yield the product polyesters. This agrees with processes found for other metal alkoxides [15-18]. Our polymerization results are superior to those reported for copper complexes with more elaborate ligands [30-33]. Literature reports for the polymerization of L-lactide using three different copper phenoxyketimine complexes at $160{ }^{\circ} \mathrm{C}$ have produced PLLA of $M_{n}=$ 2200, 4500 and $6500 \mathrm{~g} / \mathrm{mol}$ [30], which suggests that our results are superior in terms of $M_{n}$ (Table 4). Also, the molecular weights of these polymers are much lower than PLLA from common initiators such as $\left[\mathrm{Al}(\mathrm{OiPr})_{3}\right]\left(M_{n}=90000 \mathrm{~g} / \mathrm{mol}\right)$ [9]. This may be due to the higher electrophilicity of the metal center when compared with Cu-HMBBD and more favorable coordination and insertion into the L-lactic acid monomers. Therefore, for the production of higher molecular weight PLLA, more electropositive metal centers and electron withdrawing groups attached to the Schiff base are required.

\subsection{Kinetics of polymerization}

We have performed kinetic studies for the polymerization of L-lactide using $\mathrm{Cu}-\mathrm{HMBBD}$ as the catalyst in the presence of

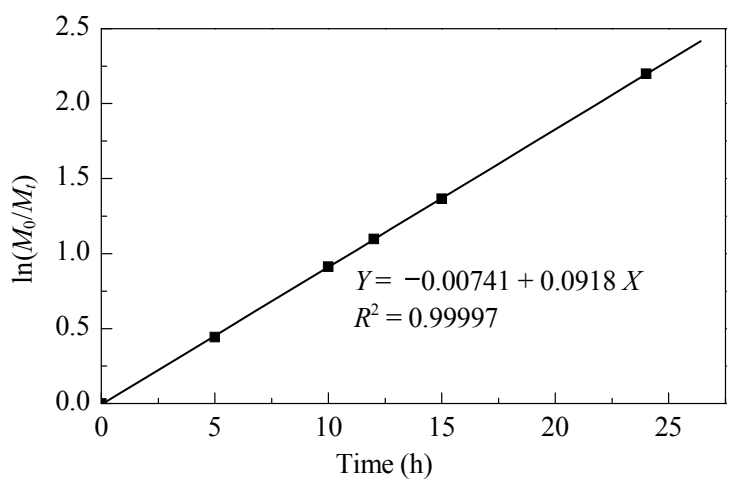

Fig. 6. Semi-logarithmic plot of L-lactide conversion catalyzed by $\mathrm{Cu}-\mathrm{HMBBD}$ in the presence of $\mathrm{BnOH}:[\mathrm{LA}]_{0} /[\mathrm{Cu}] /[\mathrm{BnOH}]=100 / 1 / 1$.

$\mathrm{BnOH}$ as initiator in the ratio $[\mathrm{LA}] /[\mathrm{Cu}] /[\mathrm{BnOH}]=100 / 1 / 1$. The results are depicted in Fig. 6.

This plot implies that the polymerization reaction obeys first order kinetics as the $\ln \left(M_{0} / M_{t}\right)$ vs time plot is linear. The apparent rate constant ( $k_{\text {app}}$ ) may be calculated from the slope of this plot. The $k_{\text {app }}$ for the L-lactide polymerization was found to be $0.0918 \mathrm{~h}^{-1}$.

\subsection{Mechanism of polymerization}

Considering the experimental findings for the ROP of L-lactide under the conditions mentioned, the polymerization may proceed by the mechanism outlined in Scheme 5 . The copper complex (Cu-HMBBD) produces active species in step 2 through fast interactions with lactide and benzyl alcohol. The active species subsequently forms an intermediate through a rearrangement in step 3 , and then in step 4, ring opening of lactide occurs to give a benzyl ester at one end. Ring opening of another molecule of lactide occurs in step 5 as in step 2. Subsequent additions of lactide produce PLLA.

\section{Conclusions}

The copper complex Cu-HMBBD was synthesized and characterized and is a good catalyst for the ring-opening polymerization of L-lactide in the presence of benzyl alcohol. The copper complex Cu-HMBBD is inactive in the absence of benzyl alcohol and, in the presence of two or four equivalent benzyl alcohol in the polymerization reaction, the molecular weights reduce to one half and one quarter, respectively. All the PLLA produced by the ROP of L-lactide has a high molecular weight and greater than $80 \%$ conversion rate.

\section{Acknowledgments}

The authors are grateful to Ravenshaw University and National Institute of Technology, Raipur for providing research facilities.

\section{References}

[1] Szwarc M. Nature, 1956, 178: 1168 


\section{Graphical Abstract}

Chin. J. Catal., 2015, 36: 764-770 doi: 10.1016/S1872-2067(14)60293-X

\section{Synthesis and structural studies of copper(II) complex supported by-ONNO- tetradentate ligand: Efficient catalyst for the} ring-opening polymerization of lactide

Anita Routaray, Nibedita Nath, Somanath Mantri, Tungabidya Maharana*, Alekha Kumar Sutar*

Ravenshaw University, India; National Institute of Technology, India

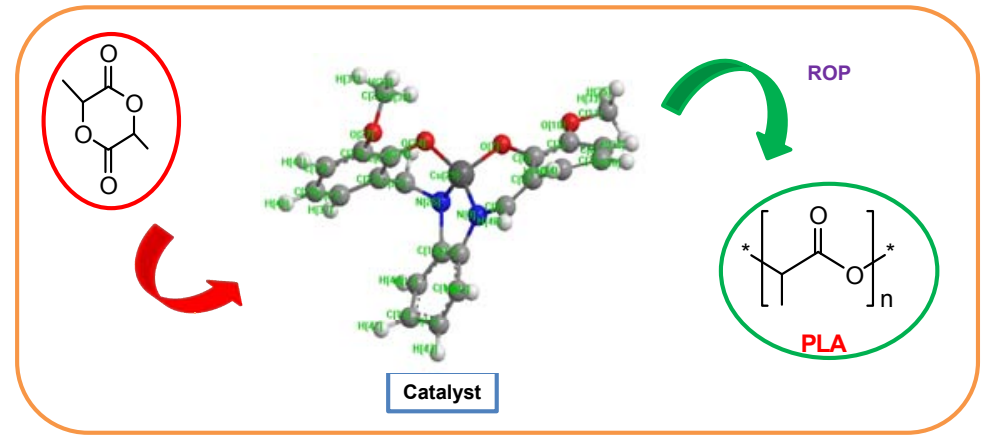

This perspective describes the synthesis, characterization and catalytic studies of copper complex supported by -ONNO- tetradentate Schiff base, towards ring-opening polymerization of lactide.

[2] Matyjaszewski K, Davis T P. Handbook of Radical Polymerization. Wiley-Interscience, Hoboken, 2002

[3] Grubbs R H. Angew Chem Int Ed, 2006, 45: 3760

[4] O’keefe B J, Hillmyer M A, Tolman W B. J Chem Soc, Dalton Trans, 2001: 2215

[5] Kubisa P, Penczek S. Prog Polym Sci, 1999, 24: 1409

[6] Kharas G B, Sanchez-Riora F, Soverson D K. Polymers of Lactic Acid. In: Mobley D P ed. Plastics from Microbes. Hanser Publishers, München, Germany, 2004

[7] Pilone A, Press K, Goldberg I, Kol M, Mazzeo M, Lamberti M. J Am Chem Soc, 2014, 136: 2940

[8] Hancock S L, Mahon M F, Jones M D. Dalton Trans, 2013, 42: 9279

[9] Dubois Ph, Jacobs C, Jérôme R, Teyssié Ph. Macromolecules, 1991, 24: 2266

[10] Sutar A K, Maharana T, Dutta S, Chen C T, Lin C C. Chem Soc Rev, 2010, 39: 1724

[11] Sun Y Y, Wang L, Yu D W, Tang N, Wu J C. J Mol Catal A, 2014, 393 : 175

[12] Liang Z H, Zhang M, Ni X F, Li X, Shen Z Q. Inorg Chem Commun, 2013, 29: 145

[13] Gao Y, Dai Z R, Zhang J J, Ma X X, Tang N, Wu J C. Inorg Chem, 2014, 53: 716

[14] Wojtaszak J, Mierzwicki K, Szafert S, Gulia N, Ejfler J. Dalton Trans, 2014, 43: 2424

[15] Chisholm M H, Eilerts N W, Huffman J C, Iyer S S, Pacold M, Phomphrai K. J Am Chem Soc, 2000, 122: 11845

[16] Dove A P, Gibson V C, Marshall E L, Rzepa H S, White A J P, Williams D J. J Am Chem Soc, 2006, 128: 9834

[17] Williams C K, Breyfogle L E, Choi S K, Nam W, Young V G Jr, Hillmyer M A, Tolman W B. J Am Chem Soc, 2003, 125: 11350

[18] Petrus R, Sobota P. Organometallics, 2012, 31: 4755

[19] Biernesser A B, Li B, Byers J A. J Am Chem Soc, 2013, 135: 16553

[20] Lee E J, Lee K M, Jang J, Kim E, Chung J S, Do Y, Yoon S C, Park S Y.J Mol Catal A, 2014, 385: 68
[21] Sattayanon C, Sontising W, Jitonnom J, Meepowpan P, Punyodom W, Kungwan N. Comp Theor Chem, 2014, 1044: 29

[22] Chen H Y, Liu M Y, Sutar A K, Lin C C. Inorg Chem, 2010, 49: 665

[23] Tsai C Y, Du H C, Chang J C, Huang B H, Ko B T, Lin C C. RSC Adv, 2014, 4: 14527

[24] Chen H Y, Peng Y L, Huang T H, Sutar A K, Miller S A, Lin C C. J Mol Catal A, 2011, 339: 61

[25] Mou Z H, Liu B, Wang M Y, Xie H Y, Li P, Li L, Li S H, Cui D M. Chem Commun, 2014, 50: 11411

[26] Abbina S, Du G D. ACS Macro Lett, 2014, 3: 689

[27] Fliedel C, Vila-Viçosa D, Calhorda M J, Dagorne S, Aviles T. ChemCatChem, 2014, 6: 1357

[28] Hill M S, Hitchcock P B, Pongtavornpinyo R. Inorg Chem, 2007, 46: 3783

[29] Appavoo D, Omondi B, Guzei I A, Van Wyk J L, Zinyemba O, Darkwa J. Polyhedron, 2014, 69: 55

[30] John A, Katiyar V, Pang K, Shaikh M M, Nanavati H, Ghosh P. Polyhedron, 2007, 26: 4033

[31] Routaray A, Nath N, Maharana T, Sutar A K. J Macromol Sci, Part A Pure Appl Chem, 2015, accepted

[32] Bhunora S, Mugo J, Bhaw-Luximon A, Mapolie S, Van Wyk J, Darkwa J, Nordlander E. Appl Organomet Chem, 2011, 25: 133

[33] Chen L L, Ding L Q, Zeng C, Long Y, Lü X Q, Song J R, Fan D D, Jin W J. Appl Organomet Chem, 2011, 25: 310

[34] Whitehorne T J J, Schaper F. Inorg Chem, 2013, 52: 13612

[35] Gupta K C, Sutar A K. Coord Chem Rev, 2008, 252: 1420

[36] Gupta K C, Sutar A K, Lin C C. Coord Chem Rev, 2009, 253: 1926

[37] Grivani G, Akherati A. Inorg Chem Commun, 2013, 28: 90

[38] Sutar A K, Das Y, Pattnaik S, Routaray A, Nath N, Rath P, Maharana T. Chin J Catal (催化学报), 2014, 35: 1701

[39] Fraile J M, Mayoral J A, Royo A J, Salvador R V, Altava B, Luis S V, Burguete M I. Tetrahedron, 1996, 52: 9853

[40] Alamri H, Zhao J P, Pahovnik D, Hadjichristdis N. Polym Chem, 2014, 5: 5471 